\title{
Convocação da mais armada
}

/////////////////I: Andrea Limberto Leite ${ }^{1}$

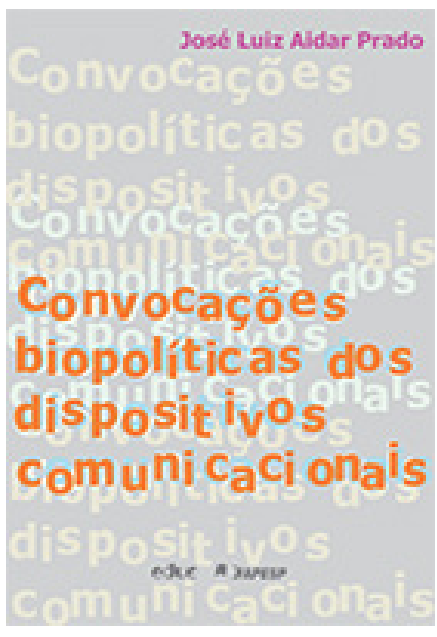

\section{Resenha}

PRADO, J. L. A. Convocações biopolíticas dos dispositivos comunicacionais. São Paulo: Educ; São Paulo: Fapesp, 2013.

1. Andrea Limberto Leite é doutora em comunicação e pósdoutoranda na Escola de Comunicações e Artes da Universidade de São Paulo/Brasil (bolsista Fapesp), com o projeto Nos termos da interdição. E-mail: andrealimberto@gmail.com 
Resumo

O novo livro do pesquisador José Luiz Aidar Prado, Convocações biopolíticas dos dispositivos comunicacionais, nos coloca cruamente diante da problemática do chamado, direcionado aos sujeitos, a integrar discursos em circulação, em que se acomodam também especificamente circulações discursivas com a finalidade de fazer consumir.

\section{Palavras-chave}

Dispositivos comunicacionais, comunicação, biopolítica, discursos.

Abstract

The most recent work by researcher José Luiz Aidar Prado, Convocações biopolíticas dos dispositivos comunicacionais (freely translated as Biopolitic convoking of communicational dispositives) puts the reader straight in the face of the calling to enter circulating discourses. They are directed to all subjects and also accomodate the discourses with urgence for consumption.

\section{Keywords}

Communicative devices, communication, biopolitics, discourses. 
O novo livro do pesquisador José Luiz Aidar Prado nos coloca cruamente diante da problemática do chamado, direcionado aos sujeitos, a integrar discursos em circulação, em que se acomodam também especificamente circulações discursivas com a finalidade de fazer consumir. Entramos com o corpo e com o psiquismo, movidos numa única pulsão que os atravessa. Se a ação incitada é aquela de consumir, incorporar, integrar, deglutir, devorar, ela se dirige àquele que se identifica através desse processamento. E, num movimento de recobrimento, na medida em que esse sujeito atende à convocação, ele igualmente identifica-se e consome de si. Visto então que o processo se completa em consumir-se, incorporar-se, integrar-se, deglutir-se, devorar-se.

Observando tais processos de convocação nos discursos midiáticos, o autor faz um brilhante trabalho utilizando como estopim especialmente pesquisa de base realizada sobre revistas semanais, inclusive com dados que haviam sido levantados nos trabalhos anunciados no próprio livro e intitulados A invenção do Mesmo e do Outro na mídia semanal (PRADO, 2008) e Regimes de visibilidade em revistas (PRADO, 2011), realizados no âmbito do grupo Um dia, sete dias - Grupo de pesquisas em mídia impressa²

2. http://www4.pucsp. br/ umdiasetedias/ São abordadas, entre outras, as revistas Veja, IstoÉ, Carta Capital e Época - além do destaque para revistas segmentadas por gênero, como Men's Health, Nova, Claudia e Marie Claire. A mídia semanal é observada como rico lastro para uma argumentação sobre discursos circulantes. A análise se amplia e se aplica à verificação de discursos 
comunicacionais, envolvendo, assim, jornais, publicidades e vídeos, entre outros exemplos que incrustam a obra.

Estão em questão os discursos comunicacionais como espaço privilegiado para que se remonte uma arena de batalha, de disputa no poder simbólico. Ela remonta a um espaço público, na medida em que o entendimento das convocações que anunciávamos deve ser comum e socialmente inteligível. Para além disso, chamamos de batalha o processo argumentativo e coercitivo de que o exposto tenha efeito de engajamento.

Chegamos à perspectiva trazida desde o título do livro, que é a de uma determinação política. As convocações midiáticas relacionamse à apropriação dos corpos e à presunção de sua animação e energização na disposição política. Os discursos midiáticos trazem diretrizes para o comportamento dos corpos, e o que se decide sobre eles é estratégico, no sentido de que a política é entendida espraiadamente em todos os níveis microfísicos de poder.

Poderia enganar-se aquele que parasse nesse primeiro nível mais superficial de leitura do livro, pressupondo exclusiva e prioritariamente um controle dos media sobre os sujeitos, passivos no atendimento às convocações. No entanto, o que se revela é um procedimento ativo de identificação que implica a doação e o envolvimento perpassado na pulsão biológica. Por isso, dizíamos, há um recorte dos corpos em doação política da própria carne para circulação. Ainda assim, devemos ter em mente que essa é uma descrição do próprio processo de representação, indistinta da possibilidade de ser. Ser, e circular, só seria possível na linguagem.

A partir disso podemos dizer que o livro todo é um enorme gancho que fisga o leitor pelo estômago fazendo acompanhar os movimentos das convocações comunicacionais. Quisemos dizer pelo estômago para passar a sensação de que dos raciocínios descritos não podem ser vistos de fora, como leitor, como sujeito. A linguagem utilizada no livro passa da abordagem teórica aos exemplos e volta à teoria de maneira a repetir o cerco identitário dos sujeitos. Se o leitor não se apercebe através da recuperação feita de teorias do discurso, da psicanálise, da antropologia, da comunicação, deve então certamente se ver com os exemplos que retomam questões de gênero, raça e sexualidade, principalmente. 
O que está privilegiado na forma com que o livro está escrito é a ação de fazer perceber as implicações na carne do pulsar das convocações descritas. Assim, é possível situar a "fodona" de Nova, em seu imaginado infinito poder sedutor, alinhada à descrição dos tipos de discurso apontados por J. Lacan e à recuperação de elementos das teorias representacionais. Da mesma forma, a fantasia "na lama e na cama, longe da roubada" com a ascensão de discursos hegemônicos. E, ainda, coaduna o a mais do gozo com um "improved tigrão".

O livro é bem escrito e tem uma leitura fluída, ao mesmo tempo que apresenta níveis de profundidade que podem ser acessados à medida que o leitor conheça a remissão a densas teorias, citadas literalmente ou não. Conceitos complexos são incorporados no texto de maneira direta, indicam saídas e apontam caminhos para os leitores que não os percorreram antes. Pode ser assim uma obra densa e ao mesmo tempo reta. Assim também podemos considerar que seja uma obra rica e original, especialmente no quesito da costura proposta entre autores.

O autor não se retrai em trabalhar com os conceitos e se apropria deles de maneira rica mas também complexa e direta, sofisticada e escancarada, pontuando o que pode especificamente recuperar. "Se alguma ênfase deve ser dada à Semiótica não é de sua pretensão de ser a ciência das ciências e das artes, mas a de uma disciplina que estude os novos regimes textuais de visibilidade e de interação que regem as sociedades atuais" (PRADO, 2013, p. 103).

No livro, encontra-se favorecida a relação entre conceitos que tentaram organizar na área dos estudos de linguagem e da psicanálise a representação sobre o eu e a circulação discursiva. São acionados, assim, autores como J. Lacan, G. Deleuze, J. Derrida, P. Charaudeau, E. Laclau e C. Mouffe e J. Rancière. Mas é na perspectiva de pensar o funcionamento da linguagem como dispositivo de controle, informada especialmente pela obra de $\mathrm{M}$. Foucault, L. Althusser e G. Agamben, que são marcadas as referidas representação do eu e circulação discursiva. E o apontamento que consideramos mais relevante é a ideia de que o dispositivo comunicacional implica um e outro numa equação de dois termos, 
que os aciona a ambos imaginariamente numa amarração, num nó. A ideia de controle é viva nesse ponto, animada pelos discursos voltados a fazer agir e emergindo das modalizações.

A sequência dos capítulos da obra é tão surpreendente quanto bem alinhavada. Ela se abre colocando em questão diretamente a relação entre visibilidade e convocação. Está na base do chamado à convocação o desejo por uma circulação visível; há um desejo por visibilidade enquanto se é tomado por uma convocação. Surgem efeitos de quando se atende a essas convocações, e eles aparecem nos termos de imperativos como "consuma", "atualize", "troque". Assim, o autor pôde apresentar gradações entre convocações hegemônicas e não hegemônicas.

No segundo capítulo, Prado aborda, tendo aberto a questão da visibilidade de um outro não hegemônico, uma situação que chamou de um Outro invisível, um Mesmo visível. Entende-se que o processo de invisibilidade está relacionado à politização da vida e à marginalização de sujeito em relação ao desenho social. Reforçase, nesse sentido, que a vida dos sujeitos está em questão como uma vinculação política, atrelada a preceitos de organização particulares e de inserção dos corpos.

Como terceiro capítulo da obra, desenha-se o campo de batalha em que as disputas políticas por visibilidade são travadas: os dispositivos midiáticos em sua plenitude de articulação, estratégias de representação e enquadramento do mundo. É nesse sentido que a inserção política dos corpos mostra seu engajamento, que é de natureza discursiva. Há também um caráter desse engajamento que não deve ser desconsiderado, que é sua atuação como dispositivo. Isso significa entender que as convocações de que trata o livro estão relacionadas a procedimentos discursivos e dizer de uma vez só sobre o político, controle e engajamento dos sujeitos no discurso, tratando-se de um conceito caro na articulação do livro.

A partir de uma outra perspectiva implicada no olhar sobre os discursos, aquela de uma topologia, o autor apresenta a ideia de um mapa. Anuncia, no quarto capítulo, o mapa da mina-vidaclipe: do pequeno truque à profanação. Tendo situado anteriormente os discursos hegemônicos em relação aos sujeitos, a condição de 
invisibilidade do outro, mais o terreno de batalha dos discursos midiáticos, o autor vai tratar da possibilidade de profanação. Tratase de desafiar o capitalismo como religião e o valor abstrato das produções e produtos.

Dito de uma outra forma, esse mapa proposto só é possível por conta de uma performatividade dos media, uma modalização relacionada ao fazer através da argumentação no discurso. O autor recorre especialmente a P. Ricoeur e J. Austin para pensar o conceito de performance dos media conforme o processo argumentativo de todo o dizer.

Nesse sentido, vai analisar especificamente a construção da realidade em Veja, concentrando-se nos imaginários de uma sociedade de controle, dos media como novos aparelhos de discursivização e do reforço de um discurso que aponta e marca diretrizes para a ação.

Um discurso específico é utilizado como exemplo privilegiado de coalizador dos desejos de ser, aquele do poder da inteligência como modalizador do sucesso. Num duplo reforço de discurso hegemônico e de reforço à valorização de recursos de controle, concentra-se sobre a inteligência dos processos de controle e na construção das diretrizes para a vontade, atenção e disciplina.

Da mesma forma, agora como objeto de desejo eleito, um nome aparece como o algo a mais a ser buscado, um fator privilegiado (como um $X$ factor), a busca do tsuj; trata-se do extra necessário para uma circulação de sucesso. A lógica da circulação da diferença indica que "o termo capital queima a diferença para mover-se".

A faceta mais original do livro vem ao final, quando o autor procura apontar as possibilidades para uma nova política ou nova forma de exercer a política. Sob o jugo de um supereu que incita o gozo, o efeito político é acionado através da culpa em ver as imagens representadas. É a manifestação do sentimento de culpa pelo prazer em concretizar a representação. Isso repõe para os sujeitos, num movimento de retorno, e faz que estes estejam eternamente amarrados à própria dinâmica da representação, em todos os seus ciclos. 
Assim, concluímos considerando que a leitura de Convocações biopolíticas dos dispositivos comunicacionais interessa para pensarmos como lidar com a política das imagens e da palavra no sentido que encarnam dispositivos de visibilidade. Podem derivar disso também uma maior autoconsciência sobre os termos das equações imaginárias que nos engajam e a abertura para que se lide com a figura de um Outro ameaçador. Nessa perspectiva, entendemos a necessidade do trabalho com as dinâmicas de consumo, associada à lógica de circulação discursiva, em que o "Consumo é o nome da ação de resposta pragmática às modalizações dos dispositivos" (PRADO, 2013, p. 161).

Podemos, ainda, fechar esta resenha dizendo que durante todo o livro o apelo subentendido das convocações é aquele contra a morte. Narrativizamos seu apelo e o performatizamos no sentido de talvez garantir a segurança sobre um abismo, um buraco. Queremos citar ainda uma iniciativa inovadora: foi feito o trabalho de preparação da versão do livro em $e$-book, estando disponível no formato epub. 


\section{Referências}

PRADO, J. L. A. A invenção do Mesmo e do Outro na mídia semanal. DVD. São Paulo: PUC-SP (Um dia, sete dias - Grupo de pesquisas em mídia impressa), 2008.

Regimes de visibilidades em revistas. DVD. São Paulo: PUC-SP (Um dia, sete dias - Grupo de pesquisas em mídia impressa), 2011. 